\title{
Characterization of a Tomato Protein Kinase Gene Induced by Infection by Potato spindle tuber viroid
}

\author{
Rosemarie W. Hammond and Yan Zhao \\ United States Department of Agriculture, Agricultural Research Service, Molecular Plant Pathology \\ Laboratory, Beltsville, MD 20705, U.S.A. \\ Accepted 25 May 2000.
}

\begin{abstract}
Viroids-covalently closed, circular RNA molecules in the size range of 250 to 450 nucleotides-are the smallest known infectious agents and cause a number of diseases of crop plants. Viroids do not encode proteins and replicate within the nucleus without a helper virus. In many cases, viroid infection results in symptoms of stunting, epinasty, and vein clearing. In our study of the molecular basis of the response of tomato cv. Rutgers to infection by Potato spindle tuber viroid (PSTVd), we have identified a specific protein kinase gene, $p k v$, that is transcriptionally activated in plants infected with either the intermediate or severe strain of PSTVd, at a lower level in plants inoculated with a mild strain, and not detectable in mock-inoculated plants. A full-length copy of the gene encoding the 55-kDa PKV (protein kinase viroid)-induced protein has been isolated and sequence analysis revealed significant homologies to cyclic nucleotide-dependent protein kinases. Although the sequence motifs in the catalytic domain suggest that it is a serine/threonine protein kinase, the recombinant PKV protein autophosphorylates in vitro on serine and tyrosine residues, suggesting that it is a putative member of the class of dual-specificity protein kinases.
\end{abstract}

Additional keywords: pathogenesis, protein phosphorylation.

Viroids are the smallest known pathogenic agents of plants and are distinguished from viruses by their lack of a protein coat and lack of protein coding capacity. As such, they rely upon their host for both replication and transport functions necessary to produce a systemic infection. Viroids are characterized as small, single-stranded, covalently closed, circular RNAs, ranging in size from 250 to 450 nucleotides, that replicate autonomously in vivo and assume a highly base-paired, rod-like structure in vitro. Since their discovery in the early 1970s (Diener 1971), much has been learned about their biochemical nature while their mechanism of pathogenesis remains elusive. As viroids replicate and exert pathogenic ef-

Corresponding author: Rosemarie W. Hammond; Fax: 1-301-504-5449; E-mail: rhammond@asrr.arsusda.gov

Nucleotide and/or amino acid sequence data have been deposited in the GenBank data base as accession no. AF143505.

This article is in the public domain and not copyrightable. It may be freely reprinted with customary crediting of the source. The American Phytopathological Society, 2000. fects without encoding proteins, the implication is that viroid functions are mediated through sequence and structural signals alone. One approach to investigating the relationship between viroid sequence and pathogenicity has been to introduce mutations into infectious cDNA copies of the viroid with subsequent examination of the effect on replication, pathogenicity, and movement (Owens et al. 1986, 1995, 1996; Hammond and Owens 1987; Loss et al. 1991; Hammond 1992, 1994; Gruner et al. 1995).

Viroid pathogenicity is a complex biological phenomenon that is influenced by both the viroid and host genomes, e.g., infections by different viroid strains in the same host or the same viroid strain in different hosts may be latent or result in symptoms ranging from mild to severe in intensity (Diener 1987). As the smallest known infectious agents, viroids provide a minimal genetic and biochemical system for the study of the mechanisms controlling host-pathogen interactions and the control of gene expression in plant cells.

Potato spindle tuber viroid (PSTVd) accumulates in the nuclei of infected cells (Harders et al. 1989), and its lack of mRNA activity suggests that viroids alter host metabolism by direct interaction with one or more host components. Although viroid infection is not accompanied by gross changes in nucleic acid metabolism, the concentrations of various host proteins may change markedly (Galindo et al. 1984; Diener 1987). Increased transcription of defense-related genes has been observed in viroid- infected plants and can be mimicked by the application of ethephon, an ethylene-releasing compound (Vera and Conejero 1989; Vera et al. 1989, 1993; Conejero et al. 1990; Ruiz-Medrano et al. 1992; Rodrigo et al. 1991, 1993; Tornero et al. 1993, 1994, 1996; Domingo et al. 1994; Gadea et al. 1996).

Evidence is also accumulating for the role of protein phosphorylation in viroid pathogenicity. Citrus exocortis viroid infection of tomato alters the pattern of protein phosphorylation of tomato leaf proteins (Vera and Conejero 1990). In addition, infection of susceptible host plants by PSTVd or Tobacco mosaic virus induces the phosphorylation of a hostencoded 68,000 $M_{\mathrm{r}}$ protein (Crum et al. 1988; Hiddinga et al. 1988). This protein appears to be constitutively expressed in healthy plant cells and is immunologically related to a mammalian interferon-induced, double-stranded (ds) RNAactivated, serine/threonine protein kinase (termed P68 or PKR [dsRNA-dependent protein kinase]) (Meurs et al. 1990; Langland et al. 1995, 1996). PKR has been implicated in the regulation of animal RNA virus synthesis by phosphorylation 
of the initiation factor eIF-2 in mammalian cells (Samuel 1991). Notably, viroid strains of differing pathogenicity have been shown to result in differential activation of the mammalian PKR in vitro, suggesting a possible triggering event in viroid pathogenesis (Diener et al. 1993).

How viroid infection may trigger these complex signaling pathways, thereby leading to disease induction, is currently unknown, and the role of a specific biochemical stimulus in the elicitation of a defense-related response is not always easy to establish. At the molecular level, activation of signal pathways results in the reversible phosphorylation of certain cellular proteins including pre-existing protein kinases and phosphatases, followed by induction of secondary pathways (Morgan 1989). In an attempt to dissect the role of protein phosphorylation in viroid disease development and to understand how the primary signal of viroid infection is transduced to the level of the genome and/or to the transcriptional apparatus, degenerate oligonucleotides corresponding to the conserved catalytic domains of known serine/threonine kinases were used in reverse transcription-polymerase chain reactions (RT-PCRs) of mRNA extracted from healthy tomato plants and from tomato plants infected with mild, intermediate, and severe strains of PSTVd (Diener et al. 1993). Here we report the molecular cloning and characterization of a PCR product present in viroid-infected, but not healthy, plants, characterization of genomic sequences encoding the PKV (protein kinase viroid), examination of its genomic organization and transcriptional activation in tomato, and determination of the phosphorylation activity of PKV by assays of a GST-PKV recombinant protein.

\section{RESULTS}

\section{Expressed kinase gene profiles in PSTVd-infected and healthy tomato leaves.}

The catalytic domains of eukaryotic protein kinases feature blocks of conserved amino acid sequences (Hanks et al. 1988). These linear arrays of amino acid sequence motifs are often used to design degenerate oligonucleotide primers for isolation of additional members of the protein kinase superfamily. To identify protein kinase genes that are differentially expressed in leaves of healthy and PSTVd-infected tomato plants, a pair of partially degenerate oligonucleotide primers corresponding to the subdomains VIb and VIII of the catalytic core (Fig. 1) were used to amplify partial transcripts representing putative protein kinase messengers expressed in the samples. Profiles of the amplified products are shown in Figure 2. Based on the knowledge that every RT-PCR product ranging from approximately 120 to $370 \mathrm{bp}$ between the subdomains VIb and VIII may represent expressed protein kinases in plants (Feng and Kung 1991), there appears to be at least one differentially expressed mRNA in relation to the actin control in healthy versus diseased tomato plants. It is represented by fragment S12 and appears to be induced in plants inoculated with the intermediate and severe strains of PSTVd. The fragment S12 was cloned and its nucleotide sequence determined. Within the $\mathrm{S} 12$ sequence, a motif of DFD/G for

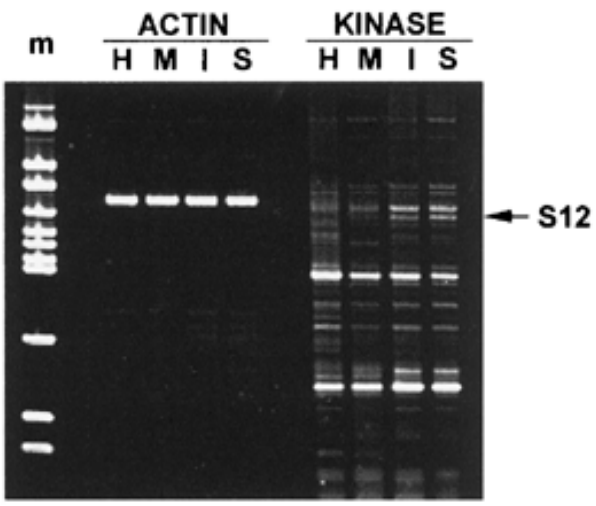

Fig. 2. Reverse transcription-polymerase chain reaction (RT-PCR) products obtained from poly(A) RNAs extracted from healthy and viroid infected tomato leaves. Poly (A) RNAs were isolated from tomato cv. Rutgers leaf tissues 4 weeks post inoculation with mild, intermediate, and severe strains of Potato spindle tuber viroid (PSTVd). RT-PCR products with primers P4 and P5 (labeled KINASE) and actin-f/actin-r (labeled ACTIN) were obtained (described in text) and are shown after ethidium bromide staining of a $5 \%$ polyacrylamide gel. Lane $\mathrm{H}=$ uninfected (mock-inoculated) tomato plants. $\mathrm{M}, \mathrm{I}$, and $\mathrm{S}=$ tomato plants inoculated with a mild, intermediate, or severe strain of PSTVd, respectively. Position of 370-bp S12 PCR fragment indicated with an arrow. $m$ $=$ molecular marker with sizes of 587, 458, 434, 359, 320, 288, 275, $267,174,102$, and $80 \mathrm{bp}$.

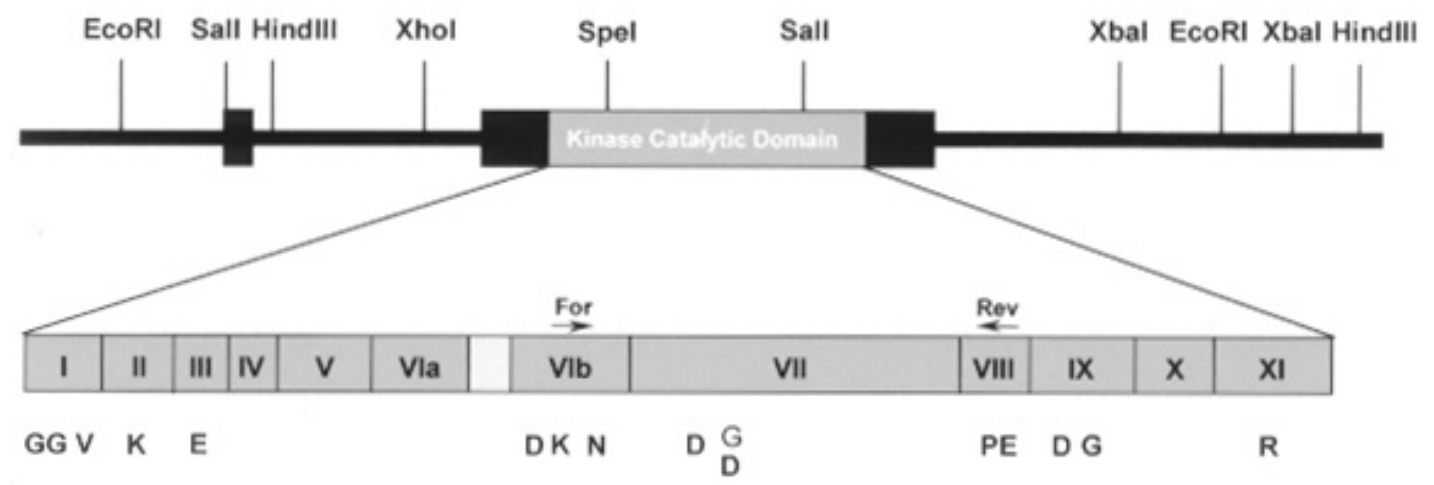

Fig. 1. Restriction map of PKV (protein kinase viroid) and flanking sequences. Thick bars, coding regions. Thin bars, intron and $5^{\prime}$ and $3^{\prime}$ flanking regions. Putative catalytic domain contains blocks of conserved amino acid sequences that are spaced to form 11 subdomains. The 15 most conserved amino acids and their relative positions are indicated below numbered subdomains. A glycine in subdomain VII is replaced by an aspartic acid. For/Rev represents location of degenerate primers used in amplification of partial kinase sequences. Lower part of diagram: white-boxed area represents a 28amino-acid, in-frame putative intron (described in text). 
subdomain VII was found as expected. The gene corresponding to clone S12 was isolated and characterized as described below.

\section{Isolation and characterization of the $p k v$ gene.}

Two identical clones were obtained after screening of about 400,000 plaques from the tomato genomic library with the cloned PCR fragment S12 as a probe. The genomic clones were mapped and part of the insert that hybridized to the probe was subcloned into a plasmid vector pBluescriptII $\mathrm{SK}(+)$ as a 3.7-kb EcoRI fragment and an overlapping 3.6-kb HindIII fragment (Fig. 1). Sequence analysis revealed that the subcloned region covers the full-length of a putative serine/threonine protein kinase gene (GenBank accession no. AF143505). Since the kinase differential display profile generated by RT-PCR (Fig. 2) revealed the transcript steady-state levels of this gene accumulated in viroid-infected plants, this gene is designated as $p k v$.

An open reading frame (ORF) search with the computer software DNASTAR indicated that the coding region of the putative kinase gene is interrupted by a single intron of $524 \mathrm{bp}$ (Fig. 1) located between two codons corresponding to $\mathrm{Glu}_{12}$ and $\mathrm{Met}_{13}$. The deduced amino acid sequence of the gene contains several blocks of conserved regions typical of serine/ threonine kinase catalytic domains. A comparison of the deduced PKV amino acid sequence to the sequences collected in an on-line protein kinase data base (Protein Kinase Resource; Smith et al. 1997) suggests that PKV is a novel member of the AGC superfamily. The AGC superfamily is mainly composed of signal-transducing kinases regulated by cyclic nucleotide cyclic AMP (cAMP) or cGMP (PKA/PKG) and kinases acti- vated by diacylglycerol and phospholipids (PKC). Within the AGC superfamily, PKV is most closely related to the flowering plant PVPK1 protein kinase family (AGC group VIII) (Fig. 3). The group VIII family kinases have some structural features that make them very unique: (i) They have an unusually long subdomain VII in their catalytic core. The subdomain VII of most of the AGC group VIII kinases spans 85 to 95 amino acids while in the majority of other kinases this region only consists of 16 to 18 amino acids. (ii2) The signature sequence in subdomain VII of AGC group VIII kinases is DFD $\left(\mathrm{D}_{241} \mathrm{FD}_{243}\right.$ in PKV) instead of DFG as found in most of other kinases. Classically, the G (Gly) was defined as one of the 15 invariant amino acids that are nested in the conserved blocks to form the framework of the catalytic core.

To estimate the complexity of the $p k v$ gene in the tomato genome, a DNA blot analysis was carried out with the digoxigenin (DIG)-labeled, 1.5-kb composite PKV ORF as a probe. As shown in Figure 4, a single 3.7-kb fragment was detected when genomic DNA was digested with EcoRI and a single 3.6-kb fragment was detected in the HindIII digest. It is likely, judging from these hybridization patterns, that $p k v$ is a singlecopy gene in the haploid tomato genome.

\section{$p k v$ transcript accumulation is induced by PSTVd infection.}

To further examine the expression patterns of the $p k v$ gene, RNA gel blot analyses were conducted with RNAs isolated from leaves of healthy tomato plants and from leaves of tomato plants inoculated with different strains of PSTVd. To ensure that equal amounts of RNA were loaded on the gel for each sample, the RNA concentrations were quantified by

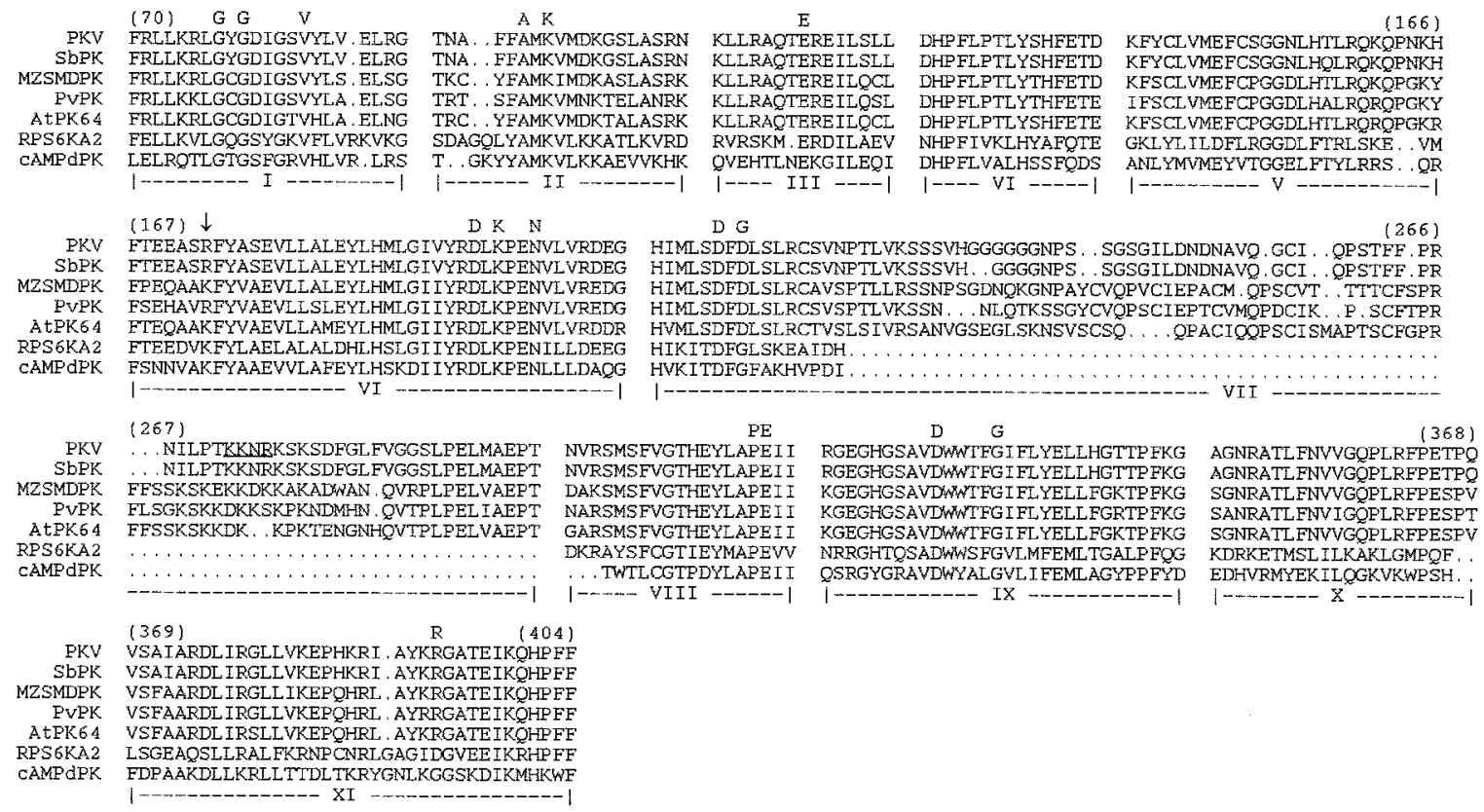

Fig. 3. Alignment of amino acid sequence of catalytic domain of protein kinases with the most homology to PKV (protein kinase viroid) in a BLAST search of the GenBank database. SbPK (Solanum berthaultii; GenBank accession no. X97980); MZSMDPK (Zea mays; M62985; Biermann et al. 1990); PvPK (Phaseolus vulgaris; J04555; Lawton et al. 1989); AtPK64 (Arabidopsis thaliana; D10937; Mizoguchi et al. 1992); RPS6KA2 (L07598; Moller et al. 1994); cAMPdPK (S41009; Franco de Oliveira et al. 1994). The 11 subdomains conserved in protein kinases are indicated by Roman numerals below the alignment; the invariant amino acid residues of serine-threonine protein kinases are shown above the alignment (Hanks and Quinn 1990). Putative nuclear localization signal is underlined (Chelsky et al. 1989). Amino acids are numbered according to the PKV open reading frame. Location of the 28amino-acid insertion is indicated by an arrow above the insertion site. The amino acid sequence represented does not include the insertion. 
spectrophotometry prior to loading, and were examined by ethidium bromide staining after electrophoresis (not shown). Consistent with the RT-PCR profile (Fig. 1), the $p k v$ transcripts are undetectable in leaves of healthy plants (Fig. 5, lane $\mathrm{H}$ ) while they are abundant in leaves of PSTVdchallenged plants (Fig. 5, lanes M, I, and S). Moreover, the elevation of the $p k v$ transcript steady-state levels found in intermediate (I) or severe (S) strain infected plants was higher than in plants infected with the mild strain (M).

\section{$p k v$ encodes a functional protein kinase with dual specificity.}

To demonstrate that the $p k v$ gene encodes a functional protein kinase, a composite ORF of the $p k v$ gene was constructed and the kinase was expressed as a GST fusion in Escherichia coli. In an initial effort to test the fusion protein for its autophosphorylation capability, we were unable to detect any phosphate-group transferring activities despite the trial of different assay conditions (data not shown). When the amino acid sequence of the PKV catalytic domain was aligned with those of other protein kinases in the data bases, we found an

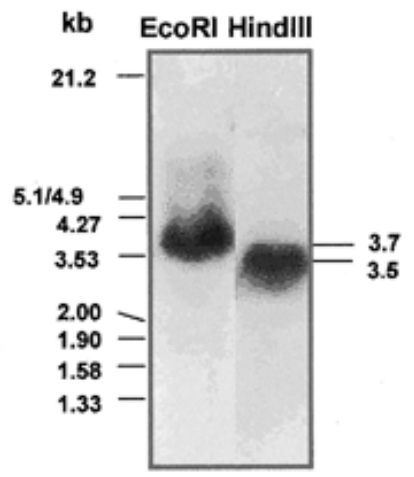

Fig. 4. DNA gel blot analysis of $p k v$-related genes in the tomato genome. Tomato genomic DNA (10 $\mu \mathrm{g}$ per lane) was digested with the indicated restriction enzymes and fractionated on a $0.8 \%$ agarose gel. Nucleic acids were blotted onto a nylon membrane and hybridized with a digoxigenin (DIG)-labeled transcript complementary to the full-length open reading frame of PKV (described in text). Lambda DNA digested with EcoRI and HindIII is the size marker.

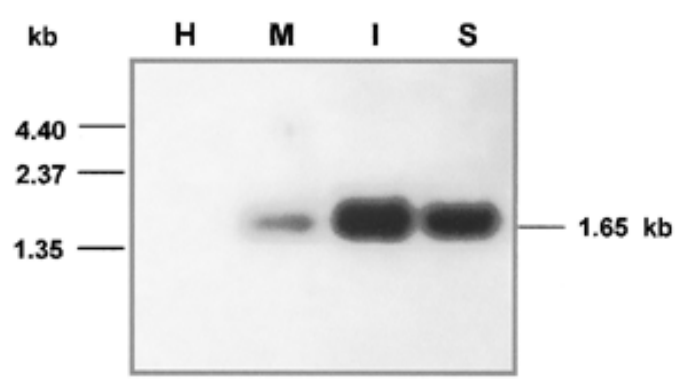

Fig. 5. $p k v$ transcript accumulation in leaf tissues of tomato inoculated with Potato spindle tuber viroid (PSTVd). Twenty micrograms of total RNA was isolated at 4 weeks post inoculation and denatured with glyoxal and dimethyl sulfoxide, fractionated on a $1 \%$ agarose gel, blotted to a nylon membrane, and hybridized to a PKV probe (described in text). H, Healthy (buffer inoculated); M, mild strain of PSTVd; I, intermediate strain of PSTVd; S, severe strain of PSTVd. Location of $p k v$ transcript is indicated. RNA molecular size markers are shown. unusual, 28-amino-acid, in-frame insertion in subdomain VIa between $\mathrm{S}_{72}$ and $\mathrm{R}_{101}$. Surprisingly, the context of the nucleotide sequence corresponding to the 28-amino-acid insert fits very well the consensus for an exon/intron border sequence (AG/gttagtacatata .........tatatttacag/AT); by removal of this 84 bp hypothetical intron, the above-mentioned 28-amino-acid insertion would be precisely eliminated from the ORF. To examine the phosphorylation activity of this shortened version of the $p k v$ ORF, a PCR-based approach was adopted to remove the 84-bp hypothetical intron. The resultant fusion construct, pGST-PKVs, was used to prepare protein for the kinase activity assay. Following the bacterial expression of the pGST$\mathrm{PKVs}$, the fusion protein was affinity purified by binding to glutathione Sepharose 4B beads and an autophosphorylation assay was carried out with $\left[\gamma_{-}{ }^{32} \mathrm{P}\right]$ ATP. Autoradiography following sodium dodecyl sulfate-polyacrylamide gel electrophoresis (SDS-PAGE; Fig. 6) revealed that the $80-\mathrm{kDa}$ fusion protein was able to phosphorylate itself with ATP as a phosphate donor (Fig. 6, lane GST-PKV). The same construct, but containing the 28-amino-acid insertion, was not capable of autophosphorylation. (Fig. 6, lane GST-PKV+28).

To show unequivocally that the kinase activity was not caused by possible contamination with bacterial proteins, a point mutation was constructed by substituting an aspartic acid for a lysine in subdomain II $\left(\mathrm{K}_{99} \rightarrow \mathrm{D}\right)$ to yield a mutant fusion construct pGST-PKVsK99D. The lysine in subdomain II is invariant in almost all known functional protein kinases and is thought to be essential in the phosphotransfer reaction (Hanks et al. 1988). Replacement of this lysine should abolish or substantially reduce the kinase activity (Taylor et al. 1992). As shown in Figure 6, lane GST-PKV K $\rightarrow \mathrm{D}$, the mutant fusion protein expressed by construct pGST-PKVsK99D failed to demonstrate any autophosphorylation activity. This suggests that $p k v$ encodes a functional protein kinase capable of phosphorylation.

To determine the identity of the phosphorylated amino acids in the autophosphorylated fusion protein, the ${ }^{32} \mathrm{P}$-labeled proteins were eluted from the gel and digested into their compositional amino acids. The phosphoamino acids in the hydrolysate were identified by thin-layer chromatography. Although

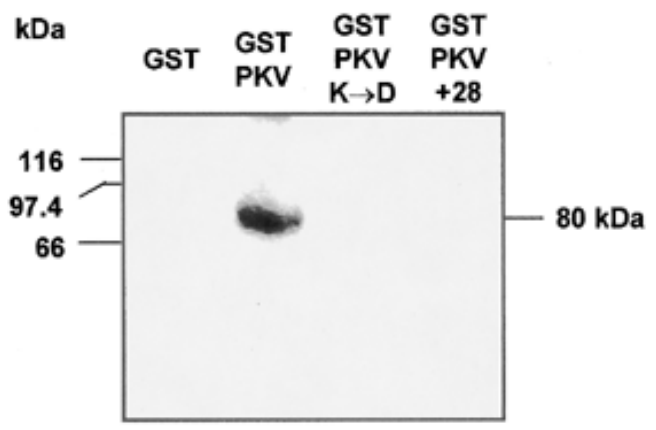

Fig. 6. Kinase assay of recombinant GST-PKV fusion proteins. Autophosphorylation of GST and GST-fusion proteins was carried out on protein bound to beads (described in text) with $\left[\gamma^{32} \mathrm{P}\right]$ ATP. Resultant autoradiogram is shown. GST, GST alone; GST-PKV, fusion protein; GST-PKV K $\rightarrow$ D, PKV containing the $\mathrm{K}_{99} \rightarrow \mathrm{D}$ mutation; GST-PKV +28 , PKV containing the 28-amino-acid insertion. Numbers at left indicate molecular mass of protein standards in kilodaltons. Number to right indicates position of the expected GST-PKV fusion protein of $80 \mathrm{kDa}$. 
the sequence motif in the catalytic domain of PKV $\left(\mathrm{D}_{223} \mathrm{LKPEN}_{228} / \mathrm{G}_{334} \mathrm{THEYLAPE}_{342}\right)$ suggested it was a serine/ threonine type kinase, the phosphoamino acid analysis clearly demonstrated that the GST-PKV fusion was phosphorylated on not only serine but also tyrosine residues (Fig. 7, lane PKV hydrolysate). Therefore, PKV is a functional protein kinase with dual specificity.

\section{DISCUSSION}

The combined use of degenerate oligonucleotides corresponding to conserved regions (VI and VIII) of the catalytic domain of serine/threonine protein kinases and differential RT-PCR of total nucleic acids derived from tomato leaves infected with PSTVd enabled us to isolate a novel tomato protein kinase gene, designated $p k v$, that is transcriptionally activated in leaves following viroid infection. $p k v$ encodes a 55$\mathrm{kDa}$ protein with features characteristic of serine/threonine protein kinases including the 11 subdomains and 14 of the 15 invariant amino acid residues in the catalytic domain (Hanks and Quinn 1990). A search of the current data bases with the amino acid sequence of the catalytic domain of PKV revealed significant homologies to the AGC group of cyclic nucleotidedependent protein kinases. The members of the group have been organized with respect to homology in the catalytic domain. The classification has proven to be an indicator of similarities in modes of regulation and substrate specificities.

The plant protein kinases with greatest similarity to PKV are SbPK, PvPK-1, MZSMDPK, and AtPK64 (Fig. 3). They share features with PKV such as the substitution of aspartic acid for glycine at residue 243 in domain VII, a longer domain VII in comparison to other members of the serine/threonine protein kinases, a putative nuclear localization signal in domain VII, and sequence similarity to cyclic nucleotidedependent protein kinases. SbPK is described in the GenBank accession information as an anther-expressed protein kinase in the potato Solanum berthaultii (GenBank accession no.

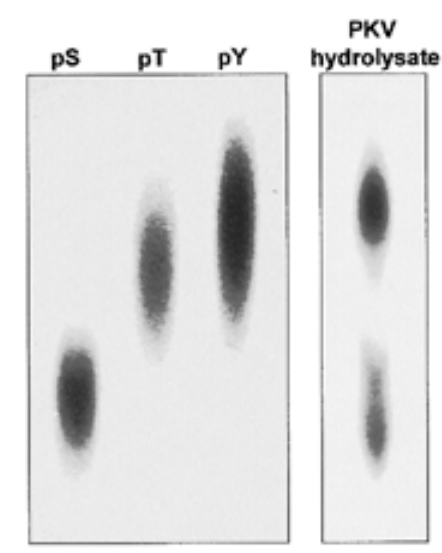

Fig. 7. Phosphoamino acid analysis of $\left[\gamma^{32} \mathrm{P}\right]$-labeled autophosphorylated GST-PKV by thin-layer chromatography. Left panel: Positions of standards phosphoserine (pS), phosphothreonine (pT), and phosphotyrosine (pY) are indicated. Right panel: Gel fragments containing phosphoprotein from kinase assay were eluted and hydrolyzed in $6 \mathrm{M} \mathrm{HCl}$ (described in text). Hydrolysate was also analyzed by thin-layer chromatography to resolve phosphorylated amino acids. Right panel (PKV hydrolysate): results of the autoradiogram.
X97980). PvPK-1 was isolated from bean cell suspension cultures treated with a fungal elicitor and may be involved in a defense response (Lawton et al. 1989). MZSMDPK was identified from mRNAs isolated from root caps of maize, but is not preferentially localized to the root cap. The distribution of transcripts is uniform but low throughout the root tip, with less abundance in mature leaves, and transcription of the gene is not regulated by light (Biermann et al. 1990). AtPK64 is expressed in a variety of organs, but there is no further information on its regulation or function (Mizoguchi et al. 1992). The similarity of PKV and related kinases to cyclic nucleotide-dependent protein kinases of mammalian cells implies involvement in the transduction of extracellular signals. Physiological studies suggest that cAMP and cGMP may have major regulatory roles in plant cells (Assmann 1995; Durner et al. 1998).

The sequence similarity of PKV to a human serine/ threonine protein kinase known as $r s k$ (RPSK6A2; p90 ${ }^{r s k}$ or ribosomal S6 kinase) and to cAMPdPK may reveal more clues as to function. $\mathrm{p} 90^{r s k}$ accumulates in the nucleus of eukaryotic cells and is implicated as a mediator of cellular proliferation by acting as a signaling intermediate in the cellular response to several growth factors (Moller et al. 1994; Xing et al. 1996). The catalytic subunit of cAMPdPK from the aquatic fungus Blastocladiella emersonii migrates to the nucleus, and the regulatory subunit is activated by binding to cAMP and its activity is developmentally regulated (Franco de Oliveira et al. 1994). A peptide sequence KKNR located at positions 300 to 303 in PKV (Fig. 3) corresponds to a putative consensus sequence $\mathrm{K}-\mathrm{R} / \mathrm{K}-\mathrm{X}-\mathrm{R} / \mathrm{K}$ for nuclear targeting of proteins (Chelsky et al. 1989) and may target PKV to the nucleus, the cellular compartment where viroid replication occurs.

No significant sequence similarities were apparent, with a BLAST, search between the putative regulatory domain region of PKV (amino terminus) and regulatory domains of other protein kinases. This region may be involved in effector binding or play a role in defining substrate specificity. In addition, there was no homology to the human PKR (Meurs et al. 1990) and the lack of dsRNA binding domains (St. Johnston et al. 1992) suggests that the PKV enzyme activity is not regulated by direct binding to PSTVd.

Although PKV appears to autophosphorylate in vitro on both serine and tyrosine residues, making it a putative member of the dual-specificity protein kinases, it does not contain the LAMMER amino acid sequence motif in subdomain $X$, in contrast to PK12, a dual-specificity plant protein kinase regulated by ethylene (Sessa et al. 1996). The significance and implications of the dual specificity remain to be determined.

Examination of nucleotide sequences in the putative promoter region revealed the presence of G-box (CACGTG) and H-box (GGTAGG) cis elements. These elements are speculated to function in the activation of phenylpropanoid biosynthetic genes involved in early responses to pathogen attack (Droge-Laser et al. 1997). The G-box also functions in the regulation of genes by developmental stimuli, such as abscisic acid, light, wounding, and pathogen signals. The biological significance of the presence of these sequence elements in the promoter of PKV can be examined by introduction of promoter/reporter fusions into transgenic tomato.

Macroscopic symptoms of viroid infection include stunting, abnormal development of root and vascular tissues, and leaf 
epinasty and deformation (Diener 1987). Many of these symptoms suggest viroid-induced disturbances in plant hormone metabolism. It has been observed that endogenous levels of ethylene, a key regulator of plant growth and development, increase in viroid-infected plants; indeed, many of the physiological and developmental alterations induced by viroid infection, including increased transcription of plant defenserelated genes and the synthesis of pathogenesis-related (PR) proteins, can be mimicked by the application of ethephon (an ethylene releasing compound) to uninfected plants (Gadea et al. 1996). Although ethylene is a known inducer of PR proteins, responsiveness to ethylene is not required for effective gene-for-gene resistance, suggesting that elicitors and pathogens use at least two different pathways for PR gene activation (Bent et al. 1992). The ethylene signal appears to be transduced via protein phosphorylation and a minimal ethylene-responsive promoter element has been defined (Eyal et al. 1993; Raz and Fluhr 1993). The putative $p k v$ promoter does not contain such an element and $p k v$ does not appear to be transcriptionally activated by treatment of tomato with ethephon (data not shown). It appears, therefore, that $p k v$ activation is not triggered by ethylene.

\section{MATERIALS AND METHODS}

\section{Inoculations with PSTVd.}

Cotyledons of tomato (Lycopersicon esculentum cv. Rutgers) were mechanically inoculated with naturally occurring mild, intermediate, and severe strains of PSTVd as previously described (Diener 1987). Control (healthy) plants were mockinoculated with buffer alone.

\section{RT-PCR.}

Poly(A) RNAs were prepared from tomato cv. Rutgers leaf tissues 4 weeks after PSTVd inoculation with the FastTrack mRNA isolation kit (Invitrogen, Carlsbad, CA). Twenty nanograms of the poly(A) RNA was reverse transcribed at $37^{\circ} \mathrm{C}$ for $90 \mathrm{~min}$ with $400 \mathrm{U}$ of M-MLV reverse transcriptase (Life Technologies, Gaithersburg, MD) in a $25-\mu$ l reaction mixture containing $10 \mathrm{mM}$ Tris- $\mathrm{HCl} \mathrm{pH} 8.3,50 \mathrm{mM} \mathrm{KCl}, 3 \mathrm{mM}$ $\mathrm{MgCl}_{2}, 1 \mathrm{mM} \mathrm{dNTPs}, 5 \mu \mathrm{g}$ of random hexamers, $20 \mathrm{U}$ of RNasin (Promega, Madison, WI), and $1 \mathrm{mM}$ dithiothreitol (DTT). Two microliters of the resultant first-strand cDNA was amplified with a pair of degenerate oligonucleotide primers corresponding to conserved amino acid sequences in subdomains VIb and VIII of the catalytic region of serine/threonine protein kinases (Hanks and Lindberg 1991) (P4 = 5' - GAT CT(TG) AAG CC(TG) TC(CT) AAT GT - 3' and P5 = 5' CTC (AT)GG (TG)GC CAA GTA CTC (AG)TG TGT (TA)CC - 3', respectively) or with primers that amplify actin transcripts (actin-f $=5^{\prime}$ GGC GAT GAA GCT CAA TCC AAA CG $3^{\prime}$ and actin-r $=5^{\prime}$ GGT CAC GAC CAG CAA GAT CAA GAC G 3'; Pennincykx et al. 1996) in a 25- $\mu$ l reaction mixture $(1 \times$ Perkin Elmer PCR buffer I [PE Applied Biosystems, Foster City, CA], $200 \mu \mathrm{M}$ dNTPs, and 20 pmol of each primer). The amplification conditions were $1 \mathrm{~min}$ at $94^{\circ} \mathrm{C}$ for denaturation, $2 \mathrm{~min}$ at $42^{\circ} \mathrm{C}$ for annealing, and $2 \mathrm{~min}$ at $72^{\circ} \mathrm{C}$ for synthesis for the $\mathrm{P} 4 / \mathrm{P} 5$ primer pair. For the actin primer pair, the annealing temperature was $55^{\circ} \mathrm{C}$. The PCR fragments were separated on a $5 \%$ polyacrylamide gel and the differentially amplified fragments were cloned into a TA plasmid vector (Invitrogen). Nucleotide sequences of cDNAs were obtained with an automated DNA sequencer (Applied Biosystems Model 373A). Sequences were analyzed and manipulated with Lasergene software by DNASTAR for the Apple Macintosh.

\section{Isolation of the pkv genomic clone.}

A cloned PCR fragment, S12, was used to screen a tomato genomic library constructed in vector EMBL-3 (a gift of Steve Tanksley, Cornell University). Approximately $4 \times 10^{5}$ plaques were screened according to a modified Benton and Davis protocol (Sambrook et al. 1989). The probe was labeled with $\left[\alpha-{ }^{32} \mathrm{P}\right] \mathrm{dCTP}$ with the Random Primers Labeling System (Life Technologies). Plaque hybridization was conducted at $42^{\circ} \mathrm{C}$ in $50 \%$ formamide ( $\mathrm{vol} / \mathrm{vol}), 6 \times \mathrm{SSC}(1 \times \mathrm{SSC}$ is $0.15 \mathrm{M} \mathrm{NaCl}$, $0.015 \mathrm{M}$ sodium citrate $\mathrm{pH} 7.0), 5 \times$ Denhardt's solution $(1 \times$ Denhardt's solution is $0.02 \%$ bovine serum albumin, $0.02 \%$ Ficoll, $0.02 \%$ polyvinylpyrrolidone), $0.5 \%$ SDS, and $100 \mu \mathrm{g}$ of denatured sonicated calf thymus DNA per ml. The filters were washed in $0.2 \times \mathrm{SSC}$ and $0.2 \%$ SDS at $65^{\circ} \mathrm{C}$. Nucleotide sequences of appropriate subclones of the genomic clone were sequenced and analyzed as above.

\section{Construction of the composite PKV ORF.}

In lieu of constructing and screening a cDNA library, a composite PKV ORF was assembled based on the information obtained from the sequence analysis of the genomic clone. The nucleotide sequences corresponding to the first and second exons were PCR amplified separately with appropriate linkers. To facilitate the manipulation, silent mutations were introduced at the fifth and sixth codons of the second exon $\left(\mathrm{S}_{17}\right.$ and $\left.\mathrm{L}_{18}\right)$ creating an XbaI site (TCG'TTA'GAC-$\left.>\mathrm{TCT}^{\prime} \mathrm{CTA}^{\prime} \mathrm{GAC}\right)$. In turn, the two amplified exons were ligated at the XbaI site to form the full-length ORF. The primer pairs used in amplification of the first and the second exons were PKNF/PKNR and PKCF/PKCR, respectively:

PKNF: 5' GGAATTCCATATGTCGACAAAGCCAACA CCATTAGAGTTATCTG $3^{\prime}$

PKNR: 5' TTCGTCTAGAGACATCGTGCTCATCTCAG ATAACTCTAATGGT 3'

PKCF: 5' ATGAGCACGATGTCTCTAGACGAA 3' PKCR: 5' GGAATTCCTAGAAGTACTCAAAGT 3'

\section{Site-directed mutagenesis of the PKV ORF at lysine ${ }_{99}$.}

Primers K2df (5' GCAATGGGACGTCATGGAT 3') and K2Dr (5' ATCCATGACGTCCATTG 3') were used for sitedirected mutagenesis. This would lead to the mutation of lysine $_{99}$ to an aspartic acid and introduction of an AatII site at the adjacent codon $\left(\right.$ valine $_{100}$ ) without changing the amino acid. With the composite $P K V$ ORF as a template, primers PKNF and K2DR were used in PCR to amplify the first half of the PKV ORF and primers K2DF and PKVCR were used to amplify the second half of the ORF. The resultant mutant PCR products were ligated at the AatII site to form a full-length, mutant $P K V$ ORF $\left(\mathrm{K}_{99} \rightarrow \mathrm{D}\right)$.

\section{DNA and RNA gel blot analyses.}

For DNA gel blot analysis, tomato genomic DNA was prepared with DNAzol (Molecular Research Center [MRC], Cincinnati, $\mathrm{OH})$. Ten micrograms of DNA was digested with restriction enzymes, fractionated on a $0.8 \%$ agarose gel, and 
transferred to a nylon membrane. For RNA gel blotting, $20 \mu \mathrm{g}$ of total RNA, extracted with TriReagent (MRC), was denatured with glyoxal and dimethyl sulfoxide (DMSO), fractionated on a $1.0 \%$ agarose gel, and blotted onto a nylon membrane. Both DNA and RNA blots were probed with a DIGlabeled transcript complementary to the full-length ORF of PKV. The hybridization for DNA gel blots was conducted at $55^{\circ} \mathrm{C}$ in a solution containing $50 \%$ formamide, $5 \times \mathrm{SSC}, 1 \times$ blocking reagent (Roche Molecular Biochemicals, Indianapolis, IN), and $0.01 \%$ SDS. The hybridization temperature for RNA gel blots was $68^{\circ} \mathrm{C}$ in the same hybridization solution as for DNA gel blots. For both DNA and RNA blots, the membranes were finally washed at $68^{\circ} \mathrm{C}$ in $0.1 \times \mathrm{SSC}$ and $0.1 \%$ SDS. DIG-labeling and chemiluminescent detection procedures were carried out according to the Genius System protocol (Roche Molecular Biochemicals).

\section{Expression of the GST-PKV fusion protein in E. coli.}

For PKV expression in E. coli, the wild type and mutant ORFs of PKV that were assembled as described above were subcloned into the NcoI/SstI sites of an expression vector pGEX-KG (Guan and Dixon 1991), a glutathione Stransferase (GST)-based vector, to yield an in-frame fusion plasmid, pGST-PKVs. The fusion plasmid was subsequently transformed into host $E$. coli strain DH5 $\alpha$.

An overnight culture of DH5 $\alpha$ carrying the fusion construct pGST-PKVs was diluted 1:100 in 2× YT medium and grown at $30^{\circ} \mathrm{C}$ with vigorous shaking until the $\mathrm{OD}_{600}$ reached 0.6 . Isopropyl $\beta$-thiogalactoside was then added to a final concentration of $1 \mathrm{mM}$ and the culture was incubated at $30^{\circ} \mathrm{C}$ for an additional $2 \mathrm{~h}$. The bacterial cells were harvested and resuspended in a lysis buffer, containing $150 \mathrm{mM} \mathrm{NaCl}, 2.5 \mathrm{mM}$

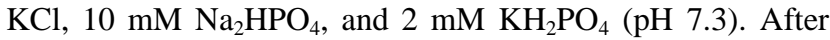
brief sonication $(5 \times, 10 \mathrm{~s}$ each), Triton $\mathrm{X}-100$ was added to the cell lysate to facilitate solubilization of the fusion proteins. The lysate was then centrifuged at $12,000 \times g$ for $10 \mathrm{~min}$ to separate the solubilized proteins from the cell debris. The soluble GST-PKV fusion was affinity purified by binding to glutathione Sepharose 4B beads essentially as described by Smith and Johnson (1988) except that a kinase buffer washing step was added before elution (see below).

\section{Kinase activity assay and phosphoamino acid analysis.}

The kinase assay was carried out directly on the GST-PKV fusion protein bound to the glutathione Sepharose 4B beads. After two rounds of $1 \times$ PBS (phosphate-buffered saline) wash, the fusion protein-bound beads were washed an additional two times with the kinase buffer ( $20 \mathrm{mM}$ Tris- $\mathrm{HCl}$ [pH 7.6], $5 \mathrm{mM}$ $\mathrm{MgCl}_{2}, 5 \mathrm{mM} \mathrm{MnSO}_{4}$ ) and resuspended in $49 \mu \mathrm{l}$ of the kinase buffer and $1 \mu \mathrm{l}$ of $\left[\gamma^{-}{ }^{32} \mathrm{P}\right] \mathrm{ATP}(10 \mu \mathrm{Ci}, 3,000 \mathrm{Ci} / \mathrm{mmol}$; Amersham Life Science, Arlington Heights, IL). The assay mixture was incubated at room temperature for $30 \mathrm{~min}$. The beads were again washed twice with the kinase buffer and the proteins were eluted with $50 \mu \mathrm{l}$ of elution buffer $(10 \mathrm{mM}$ glutathione, $50 \mathrm{mM}$ Tris- $\mathrm{HCl}$ [pH 8.0]). Ten microliters of the elution was fractionated by electrophoresis through a $10 \%$ SDS-polyacrylamide electrophoresis gel and subjected to Coomassie blue staining and autoradiography.

For phosphoamino acid analysis, the gel fragments containing the phosphoproteins were excised from the gel and the phosphoproteins were eluted by immersing the gel fragments in a solution of $50 \mathrm{mM} \mathrm{NaHCO}, 0.5 \% \mathrm{SDS}$, and $5 \mathrm{mg}$ of DTT per $\mathrm{ml}$ overnight at $20^{\circ} \mathrm{C}$. The eluted phosphoproteins were hydrolyzed with $6 \mathrm{M} \mathrm{HCl}$ at $110^{\circ} \mathrm{C}$ for $2 \mathrm{~h}$ in a $1.5-\mathrm{ml}$ glass reaction vial. The hydrolysate was dried in a vacuum centrifuge and washed twice with deionized water. A sample with about $600 \mathrm{cpm}$ was spotted onto a cellulose-backed, thin layer chromatography plate $(20 \times x 20 \mathrm{~cm}$; Analtech, Newark, DE) and resolved by chromatography with an ascending solvent of propionic acid, $1 \mathrm{M}$ ammonium hydroxide, and isopropyl alcohol (45:17.5:17.5, vol/vol/vol) (Neufeld et al. 1989).

\section{ACKNOWLEDGMENTS}

We would like to acknowledge the work of Shanta Dube in the early portion of the project with identification of the RT-PCR product designated S12. We also acknowledge D. Straney and B. Matthews for critical review of the manuscript.

\section{LITERATURE CITED}

Assmann, S. M. 1995. Cyclic AMP as a second messenger in higher plants. Plant Physiol. 108:885-888.

Bent, A. F., Innes, R. W., Ecker, J. R., and Staskawicz, B. J. 1992. Disease development in ethylene-insensitive Arabidopsis thaliana infected with virulent and avirulent Pseudomonas and Xanthomonas pathogens. Mol. Plant-Microbe Interact. 5:372-378.

Biermann, B. J., Johnson, E. M., and Feldman, L. J. 1990. Characterization and distribution of a maize cDNA encoding a peptide similar to the catalytic region of second messenger dependent protein kinases. Plant Physiol. 94:1609-1615.

Chelsky, D., Ralph, R., and Jonak, G. 1989. Sequence requirements for synthetic peptide-mediated translocation to the nucleus. Mol. Cell. Biol. 9:2487-2492.

Conejero, V., Belles, J. M., Garcia-Brejo, F., Garro, R., Hernandez-Yago, J., Rodrigo, I., and Vera, P. 1990. Signalling in viroid pathogenesis. Pages 233-261 in: Recognition and Response in Plant Virus Interactions. R. S. S. Fraser, ed. NATO ASI Series. Vol. H41. SpringerVerlag, Berlin.

Crum, C. J., Hiddinga, H. J., and Roth, D. A. 1988. Tobacco mosaic virus infection stimulates the phosphorylation of a plant protein associated with double-stranded RNA-dependent protein kinase activity. J. Biol. Chem. 263:13440-13443.

Diener, T. O. 1971. Potato spindle tuber "virus". IV. A replicating, low molecular mass RNA. Virology 45:411-428.

Diener, T. O., ed. 1987. The Viroids. Plenum Press, New York.

Diener, T. O., Hammond, R. W., Black, T., and Katze, M. G. 1993. Mechanism of viroid pathogenesis: Differential activation of the interferon-induced, double-stranded RNA-activated, $M_{\mathrm{r}} 68000$ protein kinase by viroid strains of varying pathogenicity. Biochemie 75:533538.

Domingo, C., Conejero, V., and Vera, P. 1994. Genes encoding acidic and basic class III $\beta$-1,3-glucanases are expressed in tomato plants upon viroid infection. Plant Mol. Biol. 24:725-732.

Droge-Laser, W., Kaiser, A., Lidsay, W. P., Halkier, B. A., Loake, G. J., Doerner, P., Dixon, R. A., and Lamb, C. 1997. Rapid stimulation of a soybean protein-serine kinase that phosphorylates a novel bZIP DNAbinding protein, $\mathrm{G} / \mathrm{HBF}-1$, during the induction of early transcriptiondependent defenses. EMBO J. 16:726-738.

Durner, J., Wendehenne, D., and Klessig, D. F. 1998. Defense gene induction in tobacco by nitric oxide, cyclic GMP, and cyclic ADPribose. Proc. Natl. Acad. Sci. USA 95:10328-10333.

Eyal, Y., Meller, Y., Lev-Yadun, S., and Fluhr, R. 1993. A basic-type PR1 promoter directs ethylene responsiveness, vascular and abscission zone-specific expression. Plant J. 4:225-234.

Feng, X.-H., and Kung, S.-d. 1991. Diversity of the protein kinase gene family in rice. FEBS Lett. 282:98-102.

Franco de Oliveira, J. C., Cantisani Borges, A. C., do Valle Marques, M., and Lopes Gomes, S. 1994. Cloning and characterization of the gene for the catalytic subunit of cAMP-dependent protein kinase in 
the aquatic fungus Blastocladiella emersonii. Eur. J. Biochem. 219: 555-562.

Gadea, J., Mayda, M. E., Conejero, V., and Vera, P. 1996. Characterization of defense-related genes ectopically expressed in viroid-infected tomato plants. Mol. Plant- Microbe Interact. 9:409-415.

Galindo, J. A., Smith, D. R., and Diener, T. O. 1984. A diseaseassociated host protein in viroid-infected tomato. Physiol. Plant Pathol. 24:257-275.

Gruner, R., Fels, A., Qu, F. , Zimmat, R., Steger, G., and Riesner, D. 1995. Interdependence of pathogenicity and replicability with potato spindle tuber viroid. Virology 209:60-69.

Guan, K. L., and Dixon, J. E. 1991. Eukaryotic proteins expressed in Escherichia coli: An improved thrombin cleavage and purification procedure of fusion proteins with glutathione S-transferase. Anal. Biochem. 192:262-267.

Hammond, R. W. 1992. Analysis of the virulence modulating region of potato spindle tuber viroid (PSTVd) by site-directed mutagenesis. Virology 187:654-662.

Hammond, R. W. 1994. Agrobacterium-mediated inoculation of PSTVd cDNAs onto tomato reveals the biological effect of apparently lethal mutations. Virology 201:36-45.

Hammond, R. W., and Owens, R. A. 1987. Mutational analysis of potato spindle tuber viroid reveals complex relationships between structure and infectivity. Proc. Natl. Acad. Sci. USA 84:3967-3971.

Hanks, S. K., and Lindberg, R. A. 1991. Use of degenerate oligonucleotide probes to identify clones that encode protein kinases. Methods Enzymol. 200:525-532.

Hanks, S. K., and Quinn, A. M. 1990. Protein kinase catalytic domain sequence database: Identification of conserved features of primary structure and classification of family members. Methods Enzymol. 200:38-62.

Hanks, S. K., Quinn, A. M., and Hunter, T. 1988. The protein kinase family: conserved features and deduced phylogeny of the catalytic domains. Science 241:42-52.

Harders, J., Lukacs, N., Robert-Nicoud, M., Jovin, T. M., and Riesner, D. 1989. Imaging of viroids in nuclei from tomato leaf tissue by in situ hybridization and confocal laser scanning microscopy. EMBO J. 8:3941-3949.

Hiddinga, H. J., Crum, C. J., and Roth, D. A. 1988. Viroid-induced phosphorylation of a host protein related to a dsRNA-dependent protein kinase. Science 241:451-453.

Langland, J., Jin, S., Jacobs, B., and Roth, D. A. 1995. Identification of a plant-encoded homolog of PKR, the mammalian double-stranded RNA-dependent protein kinase. Plant Physiol. 108:1259-1267.

Langland, J. O., Langland, L. A., Browning, K. S., and Roth, D. A. 1996. Phosphorylation of plant eukaryotic initiation factor- 2 by the plant-encoded double-stranded RNA-dependent protein kinase, pPKR, and inhibition of protein synthesis in vitro. J. Biol. Chem. 271: 4539-4544.

Lawton, M. A., Yamamoto, R. T., Hanks, S. K., and Lamb, C. J. 1989. Molecular cloning of plant transcripts encoding protein kinase homologs. Proc. Natl. Acad. Sci. USA 86:3140-3144.

Loss, P., Schmitz, M., Steger, G., and Riesner, D. 1991. Formation of a thermodynamically metastable structure containing hairpin II is critical for infectivity of potato spindle tuber viroid RNA. EMBO J. 10: 719-727.

Meurs, E., Chong, K., Galabru, J., Thomas, N. S. B., Kerr, I. M., Williams, B. R. G., and Hovanessian, A. G. 1990. Molecular cloning and characterization of the human double-stranded RNA-activated protein kinase induced by interferon. Cell 62:379-390.

Mizoguchi, T., Hayashida, N., Yamaguchi-Shinozaki, K., Harada, H., and Shinozaki, K. 1992. Nucleotide sequence of a cDNA encoding a protein kinase homologue in Arabidopsis thaliana. Plant Mol. Biol. 18:809-812.

Moller, D. E., Xia, C. H., Tang, W., Zhu, A. X., and Jakubowski, M. 1994. Human rsk isoforms: cloning and characterization of tissuespecific of tissue-specific expression. Am. J. Physiol. 266:351-359.

Morgan, N. G. 1989. Cell Signalling. Guilford Press, New York.

Neufeld, E., Goren, H. J., and Boland, D. 1989. Thin-layer chromatography can resolve phosphotyrosine, phosphoserine, and phosphothreonine in a protein hydrolyzate. Anal. Biochem. 177:138-143.

Owens, R. A., Chen, W., Hu, Y., and Hsu, Y.-H. 1995. Suppression of potato spindle tuber viroid replication and symptom expression by mutations which stabilize the pathogenicity domain. Virology 208:
554-564.

Owens, R. A., Hammond, R. W., Gardner, R. C., Kiefer, M. C., Thompson, S. M., and Cress, D. E. 1986. Site-specific mutagenesis of potato spindle tuber viroid cDNA. Plant Mol. Biol. 6:179-192.

Owens, R. A., Steger, G., Hu, Y., Fels, A., Hammond, R. W., and Riesner, D. 1996. RNA structural features responsible for potato spindle tuber viroid pathogenicity. Virology 222:144-158.

Pennincykx, I. A. M. A., Eggermont, K., Terras, F. R. G., Thomma, B. P. H. J., de Samblanx, G. W., Buchala, A., Métraux, J.-P., Manners, J. M., and Broekaert, W. F. 1996. Pathogen-induced systemic activation of a plant defensin gene in Arabidopsis follows a salicylic acidindependent pathway. Plant Cell 8:2309-2323.

Raz, V., and Fluhr, R. 1993. Ethylene signal is transduced via protein phosphorylation events in plants. Plant Cell 5:523-530.

Rodrigo, J. Vera, P., Frank, K., and Conejero, V. 1991. Identification of the viroid-induced tomato pathogenesis-related (PR) protein P23 as the thaumatin-like tomato protein NP24 associated with osmotic stress. Plant Mol. Biol. 16:931-934.

Rodrigo, I., Vera, P., Tornero, P., Hernandez-Yago, J., and Conejero, V. 1993. cDNA cloning of viroid-induce pathogenesis-related protein $\mathrm{P} 23$. Characterization as a vacuolar antifungal factor. Plant Physiol. 102:939-945.

Ruiz-Medrano, R., Jimenez-Moraila, B., Herrera-Estrella, L., and Rivera-Bustamante, R. F. 1992. Nucleotide sequence of an osmotin-like cDNA induced in tomato during viroid infection. Plant Mol. Biol. 20: 1199-1202.

Sambrook, J., Fritsch, E. F., and Maniatis, T. A. 1989. Molecular Cloning: A Laboratory Manual. 2nd ed. Cold Spring Harbor Laboratory, Cold Spring Harbor, NY.

Samuel, C. E. 1991. Antiviral actions of interferon: interferon-regulated cellular proteins and their surprisingly selective antiviral activities. Virology 183:1-11.

Sessa, G., Raz, V., Savaldi, S., and Fluhr, R. 1996. PK12, a plant dualspecificity protein kinase of the LAMMER family, is regulated by the hormone ethylene. Plant Cell 8:2223-2234.

Smith, C. M., Shindyalov, I. N., Veretnik, S., Gribskov, M., Taylor, S. S., Ten Eyck, L. F., and Bourne, P. E. 1997. The protein kinase resource. Trends Biochem. Sci. 22:444-446.

Smith, D. B., and Johnson, K. S. 1988. Single-step purification of polypeptides expressed in Escherichia coli as fusions with glutathione S-transferase. Gene 67:31-40.

St. Johnston, D., Brown, N. H., Gall, J. G., and Jantsch, M. 1992. A conserved double-stranded RNA-binding domain. Proc. Natl. Acad. Sci. USA 89:10979-10983.

Taylor, S. S., Knighton, D. R., Zheng, J., Ten Eyck, L. F., and Sowadski, J. M. 1992. Structural framework for the protein kinase family. Annu. Rev. Cell. Biol. 8:429-462.

Tornero, P., Conejero, V., and Vera, P. 1994. A gene encoding a novel isoform of the PR-1 protein family from tomato is induced upon viroid infection. Mol. Gen. Genet. 243:47-53.

Tornero, P., Conejero, V., and Vera, P. 1996. Primary structure and expression of a pathogen-induced protease (PR-P69) in tomato plants: Similarity of functional domains to subtilisin-like endoproteases. Proc. Natl. Acad. Sci. USA 93:6332-6337.

Tornero, P., Rodrigo, I., Conejero, V., and Vera, P. 1993. Nucleotide sequence of a cDNA encoding a pathogenesis-related protein, P1-p14, from tomato (Lycopersicon esculentum). Plant Physiol. 102:325.

Vera, P., and Conejero, V. 1989. The induction and accumulation of the pathogenesis-related P69 proteinase in tomato during citrus exocortis viroid infection and after chemical treatments. Physiol. Mol. Plant Pathol. 34:323-334.

Vera, P., and Conejero, V. 1990. Citrus exocortis viroid infection alters the in vitro pattern of protein phosphorylation of tomato leaf proteins. Mol. Plant-Microbe Interact. 3:28-32.

Vera, P., Hernandez-Yago, J., and Conejero, V. 1989. "Pathogenesisrelated" P1(p14) protein. Vacuolar and apoplastic localization in leaf tissue from tomato plants infected with citrus exocortis viroid: In vitro synthesis and processing. J. Gen. Virol. 70:1933-1942.

Vera, P., Tornero, P., and Conejero, V. 1993. Cloning and expression of a viroid-induced peroxidase from tomato plants. Mol. Plant-Microbe Interact. 6:790-794.

Xing, J., Ginty, D. D., and Greenberg, M. E. 1996. Coupling of the RAS-MAPK pathway to gene activation by RSK2, a growth factorregulated CREB kinase. Science 273:959-963. 